\title{
APLICAÇÃO DA MATRIZ BASICO COMO BOA PRÁTICA DE GOVERNANÇA EM INSTITUIÇÕES PÚBLICAS E PRIVADAS: DESENVOLVIMENTO DE UM APLICATIVO DE APOIO À TOMADA DE DECISÃO
}

\author{
Natan Shalom Frutuoso de Oliveira \\ Instituto Militar de Engenharia \\ Praça General Tibúrcio, 80, SE/9 - Computação \\ natan.sfo@gmail.com \\ Marcos dos Santos \\ Instituto Militar de Engenharia (IME) \\ Praça General Tibúrcio, 80, SE/9 - Engenharia de Computação \\ marcos.santos@marinha.mil.br \\ Ernesto Rademaker Martins \\ Instituto Militar de Engenharia (IME) \\ Praça General Tibúrcio, 80, SE/9 - Engenharia de Computação \\ rademaker@marinha.mil.br
}

\begin{abstract}
RESUMO
A governança se apresenta nas cúpulas de grandes instituições públicas e privadas, onde os altos gestores são responsáveis por tomar as decisões que definem o rumo que suas instituições tomarão. Este artigo busca fornecer uma ferramenta de apoio à decisão das altas administrações através do desenvolvimento de um aplicativo que possa auxiliar os decisores fornecendo um embasamento técnico para suas deliberações. Metodologicamente, a literatura apresenta diversas ferramentas matemáticas de apoio à decisão, sendo algumas delas matriciais. No presente trabalho optou-se por utilizar a Matriz BASICO, que serve para ranquear ações estratégicas de acordo com seu nível de impacto em uma organização. Espera-se trazer uma significativa contribuição para a sociedade na medida em que o aplicativo contribuirá para a melhoria da governança das organizações públicas e privadas.
\end{abstract}

Palavras-chave: Governança; Apoio à Decisão; Organização; Matriz BASICO; Alta Administração.

\begin{abstract}
Governance presents itself in the top of large public and private institutions, where high executives are responsible for taking decisions that shape the future their institutions will tread. This article attempts to provide a decision support tool for high management executives through the development of an application that may assist the decision makers by providing a technical resource for their deliberations. Methodologically, literature presents various mathematical tools for decision support, some of those being matrixial ones. In the present work, it was decided to utilize the Matrix BASICO, used to rank strategic actions according to their level of impact in an organization. It is expected that the application
\end{abstract}


brings a significant contribution to the society as it contributes to the improvement of governance in public and private organizations.

Keywords: Governance; Decision Support; Organization; Matrix BASICO; High Management.

\section{Como Citar:}

OLIVEIRA, N.S.F. de; SANTOS, M. dos; MARTINS, E.R. Aplicação da Matriz BASICO como boa prática de governança em instituições públicas e privadas: Desenvolvimento de um aplicativo de apoio à tomada de decisão. In: SIMPÓSIO DE PESQUISA OPERACIONAL E LOGÍSTICA DA MARINHA, 19., 2019, Rio de Janeiro, RJ. Anais [...]. Rio de Janeiro: Centro de Análises de Sistemas Navais, 2019.

\section{INTRODUÇÃO}

A sociedade mundial contemporânea é repleta de organizações e instituições que a compõem e regulam: de governos e multinacionais até pequenas empresas. A maioria dessas organizações possui um público que deseja atender, seja através da entrega de um produto ou da prestação de um serviço. Com a decrescente dificuldade de se abrir uma empresa e a velocidade e disponibilidade com que dados e informações relevantes são obtidas, os chefes executivos, donos e sócios dessas instituições precisam identificar novas oportunidades de crescimento e de negócio e operacionalizá-las rapidamente, podendo perder espaço de mercado para seus concorrentes caso não o façam.

A governança surge no contexto das organizações como uma tentativa de sistematizar o planejamento e execução dos planos estratégicos de uma companhia, sejam eles de curto, médio ou longo prazo, através de três pilares: Avaliação, Direcionamento e Monitoramento (NARDES; ALTOUNIAN; VIEIRA, 2014). Ao avaliar, é determinada a situação atual da organização; com o direcionamento, é traçado um plano a ser executado pelos executivos abaixo da Alta Liderança e, por fim, o monitoramento é responsável pelo acompanhamento e ajuste da execução do planejamento pela cúpula executiva.

Enquanto os EUA e países europeus já têm abordado, analisado e desenvolvido o tema da governança há quase 30 anos (HARVARD BUSINESS REVIEW, 2001), no Brasil esse ainda é um assunto pouco difundido e explorado. Com o crescente acesso da população a meios de comunicação como celulares e computadores, além do acesso mais amplo à internet, as informações sobre a administração pública têm sido divulgadas com maior abrangência e velocidade, levando a um movimento da sociedade no sentido de demandar dos governantes um aumento na transparência com os gastos públicos e uma prestação de contas mais acessível e detalhada. 


\section{PROBLEMA}

Em todo o mundo, as organizações sofrem com a dificuldade de alinhar interesses de gestores, donos e clientes, num embate em que cada parte busca o máximo proveito para si e o equilíbrio nas decisões é dificilmente atingido. Os interesses individuais, sejam de ordem financeira, de status ou poder acabam sendo colocados acima do cumprimento da missão e da saúde de longo prazo da instituição, o que coloca em risco a sua continuidade e desenvolvimento. Os executivos das companhias, que por sua função deveriam ter como objetivo maior a prosperidade da organização, comumente substituem essa prioridade por buscas de promoções e manutenção de cargos e poder, arbitrando por decisões que os beneficiem ainda que não sejam as melhores para a empresa (SAITO; SILVEIRA, 2008).

O Brasil, conhecido por seu engessamento legal e burocracia dentro e fora da esfera pública corporativa, apresenta um desafio ainda mais acentuado quando se trata de alcançar a boa governança. Os infindáveis escândalos envolvendo grandes executivos de empresas públicas, privadas, além de governantes são uma mostra clara da situação ainda muito distante da desejada em se falando do tema da Governança. Os acionistas, no caso das organizações privadas, e a população, no caso das públicas, vêm demandando cada vez mais uma prestação de contas mais transparente de como os seus recursos, confiados aos gestores, têm sido gastos e empregados.

Para auxiliar os executivos da Alta Administração nessa tarefa que é o processo decisório e, ao mesmo tempo, fornecer às partes interessadas uma justificativa técnica e impessoal, faz-se necessário o desenvolvimento e a utilização de instrumentos apoiadores à decisão. Com a tecnologia cada vez mais acessível na palma da mão, através dos smartphones, é interessante buscar uma ferramenta de gestão que contribua para a melhoria da governança nas instituições e desenvolver um aplicativo que facilite a utilização dessa ferramenta. O que nos leva ao cerne do presente trabalho: Como auxiliar os executivos da Alta Administração das organizações públicas e privadas brasileiras a estabelecer um novo patamar de governança corporativa no país?

\section{FUNDAMENTAÇÃO TEÓRICA}

A governança corporativa tem por principal objetivo trazer um maior equilíbrio de acesso às informações pelas diferentes partes interessadas numa organização, abrindo espaço para que decisões sejam arbitradas com maior impessoalidade e objetividade. Isso se desdobra em um tratamento justo a todos os clientes (ou aqueles que usufruem do serviço da empresa), transparência das operações e estruturas, além da responsabilização dos executivos encarregados da condução estratégica das instituições. Com essas ações, busca-se mitigar os erros estratégicos, que costumam advir de muito poder concentrado em uma só pessoa ou grupo de pessoas que escolhe um caminho errado e demora para corrigi-lo (DE SOUZA, 2007).

Instituições reguladoras e fomentadoras do mercado financeiro ao redor do mundo e também no Brasil desenvolveram documentos conhecidos como Códigos de Boas Práticas de Governança Corporativa. Diversas práticas de governança visando ao aperfeiçoamento das operaçãos organizacionais e melhora nos resultados foram elencadas, dentre as quais pode-se destacar: um conselho administrativo com número adequado de membros, maior participação de membros externos nesse conselho e separação entre os cargos de diretor executivo e presidente do conselho. Foi constatado que a adoção dessas recomendações dos órgãos brasileiros de governança trouxe maior valor para as companhias brasileiras de capital aberto (SILVEIRA; BARROS; FAMÁ, 2003).

A busca de mecanismos para proteger investidores, empreendedores e outras partes interessadas nas organizações é uma preocupação antiga, surgida muito antes dos 
conhecimentos formalizados no século XX. A governança corporativa, ao reunir, classificar e modelar estruturas para utilização e desenvolvimento desses mecanismos busca oferecer aos detentores de capital a possibilidade de replicar métodos já validados pela experiência e facilitar a discussão de novos métodos. Dessa forma, investidores e partes interessadas das instituições dispõem de ferramentas para resguardarem seus interesses a despeito das decisões dos gestores executivos, por vezes desalinhadas dos interesses daqueles (RICARDINO; MARTINS, 2004).

No Brasil, o setor público é notável por sua dificuldade em operacionalizar as ações que são planejadas pelos seus entes e executivos, apresentando uma estrutura organizacional engessada e rígida. O cidadão, real cliente dos serviços prestados pelas entidades públicas, tem extrema dificuldade em enxergar valor nas atividades desempenhadas pelos executivos públicos, principalmente pela falta de transparência com as contas públicas e da precária prestação de contas dos gastos públicos. Nesse cenário, a transferência do conhecimento e das experiências da governança corporativa para o setor público brasileiro torna-se um desafio cada vez mais importante para a sociedade e o país (MATIAS-PEREIRA, 2010).

Segundo Mello (2006), a governança corporativa, por se basear nos princípios de transparência, integridade e responsabilidade, pode contribuir positivamente para a melhoria do setor público brasileiro. Sua pesquisa analisa a esfera federal do país, mas seus resultados podem ser estendidos para a máquina pública brasileira em geral, pois apesar de complexa e extensa, é ainda assim passível de mudanças e melhorias. Nesse sentido, apoiar a governança com ferramentas que facilitem as tomadas de decisão dos altos gestores - também das organizações públicas - é essencial para a transformação da realidade percebida pela população brasileira, tanto na administração pública quanto na destinação e emprego dos recursos financeiros, arrecadados por meio de impostos.

Embora comumente os altos gestores não se utilizem de análises com base em dados numéricos para tomar suas decisões, essa abordagem é necessária para a melhoria da eficiência do processo decisório. A maneira mais efetiva de se tomar decisões estratégicas é buscar quantificar e medir, através de indicadores de desempenho, as ações planejadas e executadas. Assim pode-se atingir da forma mais confiável e rápida as melhores soluções para a organização (MARANHÃO; MACIEIRA, 2006).

Para Eissmann (2017), o exercício das práticas de governança corporativa tendem a reduzir a incerteza envolvida na tomada de decisão, levando ao aumento da probabilidade de alcance dos objetivos estabelecidos pela Alta Administração. Para os acionistas e a sociedade (no caso da organização pública), conceber e utilizar ferramentas que apoiem e justifiquem as decisões dos gestores é fundamental para que haja uma transparência e responsabilização adequada. Isso gera uma gestão mais confiável e estruturada, que abre caminho para novos investimentos e investidores por parte dos líderes estratégicos e dos detentores de capital, conferindo à organização uma melhor visibilidade no mercado, seja privado ou público.

A utilização de ferramentas matriciais para avaliação do comprometimento de gestores municipais e suas organizações com os princípios de governança corporativa foi realizada por Ramos e Vieira (2015). As matrizes oferecem uma forma visual, interativa e simplificada de diferentes partes interessadas no processo decisório avaliarem o cenário em que se encontram e tomarem uma decisão mais acertada, com vistas à melhor direção para a companhia. De forma semelhante, é possível desenvolver uma ferramenta matricial que apoie os decisores diretamente na escolha de quais ações trarão mais vantagem diretamente para a operação executiva.

\subsection{MATRIZ BASICO}

Segundo o Brasil (2015), a Matriz BASICO “foi desenvolvida com base no balanço 
Custos x Benefícios x Exequibilidade e procura contemplar todos os tipos de 'Clientes' das organizações". Para sua utilização, deve-se atribuir, para cada objetivo estratégico, uma nota que pode variar de 1 a 5 em cada um dos 6 critérios avaliados, sendo 1 para um sentimento muito negativo e 5 para um sentimento muito positivo. Os critérios avaliados são os seguintes: Benefícios para a organização, Abrangência, Satisfação do cliente interno, Investimentos requeridos, Cliente externo satisfeito e Operacionalização.

O atributo B (Benefícios) se refere ao impacto da solução analisada nos resultados do processo, como: redução de custos gerada, aumento na produção e redução dos defeitos. Já o atributo A (Abrangência) aborda o montante da organização (integrantes) que será beneficiado com a melhoria do processo em questão. A Satisfação (S) do cliente interno corresponde ao grau de satisfação a ser gerado nos integrantes da organização que têm alguma relação com o processo cuja melhoria está sendo estudada. Os Investimentos (I) requeridos consideram o montante dos recursos que serão necessários para a efetivação da melhoria do processo em questão. O Cliente $(\mathrm{C})$ externo satisfeito compreende o impacto que a melhoria do processo em questão terá sobre o cliente externo. Por fim, a Operacionalização $(\mathrm{O})$ significa a exequibilidade da melhoria do processo em estudo, levando em conta aspectos como: resistência à mudança, impedimentos de ordem social/cultural/legal, domínio da tecnologia requerida para tal, simplicidade da implantação e facilidade de uso dos pontos fortes da organização.

$\mathrm{Na}$ Tabela 1 a seguir encontram-se descritos parâmetros para orientar as pontuações de 1 a 5 em cada um dos 6 atributos da Matriz BASICO:

Tabela 1 - Tabela auxiliar de pontuação da Matriz BASICO

\begin{tabular}{|c|c|c|c|c|c|c|}
\hline & B & $\mathbf{A}$ & $\mathbf{S}$ & I & C & $\mathbf{O}$ \\
\hline 5 & $\begin{array}{l}\text { Benefícios de } \\
\text { vital importân- } \\
\text { cia para a sobre- } \\
\text { vivência e ex- } \\
\text { pansão dos ne- } \\
\text { gócios da insti- } \\
\text { tuição. }\end{array}$ & $\begin{array}{l}\text { Total abran- } \\
\text { gência (de } 70 \text { a } \\
100 \% \text { da insti- } \\
\text { tuição). }\end{array}$ & $\begin{array}{l}\text { Muito Grande, } \\
\text { servindo como } \\
\text { excelente refer- } \\
\text { encial dos re- } \\
\text { sultados na } \\
\text { qualidade. }\end{array}$ & $\begin{array}{l}\text { Mínimo gasto } \\
\text { (utilização) em } \\
\text { recursos dispo- } \\
\text { níveis na pró- } \\
\text { pria área ou fa- } \\
\text { cilmente com- } \\
\text { seguidos. }\end{array}$ & $\begin{array}{l}\text { Impacto positi- } \\
\text { vo muito gran- } \\
\text { de na imagem } \\
\text { da instituição } \\
\text { no relaciona- } \\
\text { mento com o } \\
\text { mercado e a } \\
\text { comunidade. }\end{array}$ & $\begin{array}{l}\text { Grande facili- } \\
\text { dade de im- } \\
\text { plantação da } \\
\text { solução, com } \\
\text { total domínio } \\
\text { da "tecnologia } \\
\text { requerida". }\end{array}$ \\
\hline 4 & $\begin{array}{l}\text { Grandes bene- } \\
\text { fícios que irão } \\
\text { resultar em sig- } \\
\text { nificativos lu- } \\
\text { cros ou avanços } \\
\text { tecnológicos. }\end{array}$ & $\begin{array}{l}\text { Abrangência } \\
\text { muito grande } \\
\text { (de } 40 \text { a } 70 \% \\
\text { da instituição). }\end{array}$ & $\begin{array}{l}\text { Grande, a pon- } \\
\text { to de gerar de- } \\
\text { monstrações de } \\
\text { reconhecimen- } \\
\text { to com a atitu- } \\
\text { de tomada. }\end{array}$ & $\begin{array}{l}\text { Algum gasto } \\
\text { (utilização) de } \\
\text { recursos pró- } \\
\text { prios (dentro } \\
\text { do orçamento } \\
\text { deste). }\end{array}$ & $\begin{array}{l}\text { Grandes refle- } \\
\text { xos diretos nos } \\
\text { processos fim } \\
\text { ou nos outros } \\
\text { processos de a- } \\
\text { poio que atin- } \\
\text { gem aos clien- } \\
\text { tes externos e o } \\
\text { meio ambiente. }\end{array}$ & $\begin{array}{l}\text { Boa facilidade } \\
\text { dependendo } \\
\text { entretanto de } \\
\text { know-how } \\
\text { tecnlogia exter- } \\
\text { na, mas de re- } \\
\text { lativa disponi- } \\
\text { bilidade no } \\
\text { mercado. }\end{array}$ \\
\hline 3 & $\begin{array}{l}\text { Benefícios de } \\
\text { razoável impac- } \\
\text { to no desempe- } \\
\text { nho da unidade } \\
\text { operacional. }\end{array}$ & $\begin{array}{l}\text { Abrangência } \\
\text { razoável (de } 20 \\
\text { a } 40 \% \text { da insti- } \\
\text { tuição). }\end{array}$ & $\begin{array}{l}\text { Médio, a ponto } \\
\text { de ser facil- } \\
\text { mente notada } \\
\text { pelos colegas } \\
\text { de trabalho. }\end{array}$ & $\begin{array}{l}\text { Gastos de re- } \\
\text { cursos além do } \\
\text { "orçamento" da } \\
\text { área mas apro- } \\
\text { vável em nível } \\
\text { imediatamente } \\
\text { superior (den- } \\
\text { tro do orça- } \\
\text { mento deste). }\end{array}$ & $\begin{array}{l}\text { Bons reflexos } \\
\text { diretos nos pro- } \\
\text { cessos finalís- } \\
\text { ticos ou nos } \\
\text { outros proces- } \\
\text { sos de apoio } \\
\text { que atingem } \\
\text { diretamente os } \\
\text { clientes exter- } \\
\text { nos e o meio } \\
\text { ambiente. }\end{array}$ & $\begin{array}{l}\text { Média facilida- } \\
\text { de dependendo } \\
\text { de know-how } \\
\text { de difícil dis- } \\
\text { ponibilidade no } \\
\text { mercado ou ra- } \\
\text { zoáveis mu- } \\
\text { danças com- } \\
\text { portamentais } \\
\text { ou da cultura } \\
\text { organizacional } \\
\text { em geral. }\end{array}$ \\
\hline 2 & $\begin{array}{l}\text { Algum benefí- } \\
\text { cio no desempe- }\end{array}$ & $\begin{array}{l}\text { Abrangência } \\
\text { pequena (de } 5\end{array}$ & $\begin{array}{l}\text { Razoável, exis- } \\
\text { te mas não che- }\end{array}$ & $\begin{array}{lrr}\text { Gastos } & \text { de } & \text { re- } \\
\text { cursos } & \text { que }\end{array}$ & $\begin{array}{l}\text { Pouco impacto } \\
\text { nos processos }\end{array}$ & $\begin{array}{l}\text { Pouca exequi- } \\
\text { bilidade, de- }\end{array}$ \\
\hline
\end{tabular}




\begin{tabular}{|c|c|c|c|c|c|c|}
\hline & $\begin{array}{l}\text { nho operacional } \\
\text { passível de ser } \\
\text { quantificado. }\end{array}$ & $\begin{array}{l}\text { a } 20 \% \text { da insti- } \\
\text { tuição). }\end{array}$ & $\begin{array}{l}\text { ga a ser facil- } \\
\text { mente notada } \\
\text { pelos colegas } \\
\text { de trabalho. }\end{array}$ & $\begin{array}{l}\text { requerem re- } \\
\text { manejamento } \\
\text { de verba/ } \\
\text { recursos do } \\
\text { orçamento da } \\
\text { instituição, a } \\
\text { nível de dire- } \\
\text { toria. }\end{array}$ & finalísticos. & $\begin{array}{l}\text { pendendo de } \\
\text { ações ou deci- } \\
\text { sões políticas } \\
\text { dentro da insti- } \\
\text { tuição, ou mu- } \\
\text { danças acentu- } \\
\text { adas de com- } \\
\text { portamentos ou } \\
\text { da cultura or- } \\
\text { ganizacional } \\
\text { em geral. }\end{array}$ \\
\hline 1 & $\begin{array}{l}\text { Benefícios de } \\
\text { pouca expressão } \\
\text { quanto a impac- } \\
\text { tos operacio- } \\
\text { nais, mas que } \\
\text { irão contribuir } \\
\text { para a dissemi- } \\
\text { nação da Quali- } \\
\text { dade na insti- } \\
\text { tuição. }\end{array}$ & $\begin{array}{l}\text { Abrangência } \\
\text { muito pequena } \\
\text { (até 5\% da } \\
\text { instituição). }\end{array}$ & $\begin{array}{l}\text { Pequeno mas o } \\
\text { suficiente para } \\
\text { contribuir para } \\
\text { a disseminação } \\
\text { da Qualidade } \\
\text { Total, na insti- } \\
\text { tuição. }\end{array}$ & $\begin{array}{l}\text { Gasto de recur- } \\
\text { sos (\$, ho- } \\
\text { mens-hora, } \\
\text { equipamentos, } \\
\text { etc.) muito } \\
\text { significativos, } \\
\text { além do previs- } \\
\text { to/orçado re- } \\
\text { querendo deci- } \\
\text { são político/es- } \\
\text { tratégica da } \\
\text { instituição. }\end{array}$ & $\begin{array}{l}\text { Nenhum refle- } \\
\text { xo perceptível } \\
\text { pelo cliente } \\
\text { externo. }\end{array}$ & $\begin{array}{l}\text { Baixíssima } \\
\text { exequibilidade, } \\
\text { dependendo de } \\
\text { ações/ decisões } \\
\text { que extrapolam } \\
\text { os limites da } \\
\text { instituição. }\end{array}$ \\
\hline
\end{tabular}

Fonte: Brasil (2015)

\section{DESENVOLVIMENTO DA APLICAÇÃO}

Para a aplicação optou-se por não se utilizar banco de dados, seja para armazenar informações pessoais de usuários ou informações inseridas pelo usuário para gerar as matrizes BASICO. Ademais, a aplicação possui 2 módulos, o principal, que apresenta a matriz BASICO para utilização e o módulo de apoio, que descreve detalhadamente como utilizar corretamente a matriz BASICO para o processo decisório.

\subsection{ABordagem TÉCNICA}

A escolha para as linguagens de desenvolvimento foi realizada buscando aliar a facilidade e familiaridade do desenvolvedor à possibilidade de gerar a aplicação em múltiplas plataformas utilizando apenas um código-fonte. Naturalmente, optou-se por linguagens orientadas a objeto, para uma modularização e desenvolvimento paralelo, além do padrão MVC de arquitetura de software, contendo: o Modelo, responsável pela manipulação dos dados; a Visualização, responsável pela interação com o usuário e o Controle, responsável por coordenar as interações intra-aplicação.

O código foi gerado utilizando o framework Ionic 4, que se utiliza das seguintes linguagens: HTML para o desenvolvimento funcional do front-end, CSS para estilização das páginas do front-end e Javascript para a lógica do back-end. Para o front-end foi também utilizado o framework Angular. Para a aplicação final foi gerado o instalador apenas para o sistema operacional Android com vistas à entrega mais rápida do produto final, mas o código-fonte pode ser utilizado como está para gerar versões Web e para iOS.

A seguir apresenta-se um exemplo de utilização da aplicação na forma de "minimundo", termo utilizado por desenvolvedores de software para descrever formalmente a realidade a ser representada pelo sistema. Neste caso, descrever-se-á tanto a situação do usuário que pode se beneficiar do uso da aplicação como o passo-a-passo necessário para utilizar corretamente a aplicação. 


\subsection{EXEMPLO DE UTILIZAÇão (MINI-MUNDO)}

O senhor Mariano da Silva, CEO da empresa Tecnologias Móveis LTDA (TM), está elaborando o planejamento estratégico e o orçamento para o próximo biênio e precisa decidir, dentre as opções de investimento disponíveis, quais priorizar no decorrer de sua gestão para maximizar o lucro da companhia ao mesmo tempo em que mantém o crescimento saudável e a longevidade da organização. A TM é especialista em criação de celulares smartphone, desenvolvendo tanto o hardware quanto o software dos seus aparelhos.

O CEO dispõe das seguintes opções: 1) Lançar um novo aparelho, o euFone XI; 2) Desenvolver um novo sistema operacional, o euOS 13; 3) Lançar campanhas de marketing do já-existente euFone X; 4) Reestruturar o quadro de funcionários, aumentando eficiência interna; 5) Patrocinar eventos globais e nacionais de grande visibilidade; 6) Criar o primeiro notebook da TM, o MequeBook; 7) Adquirir outra companhia criadora de celulares.

$\mathrm{Na}$ tela inicial da aplicação, clica-se no botão "Adicionar Linha" para adicionar uma nova linha à matriz BASICO, conforme Figura 1 a seguir:

Figura 1 - Tela inicial da aplicação

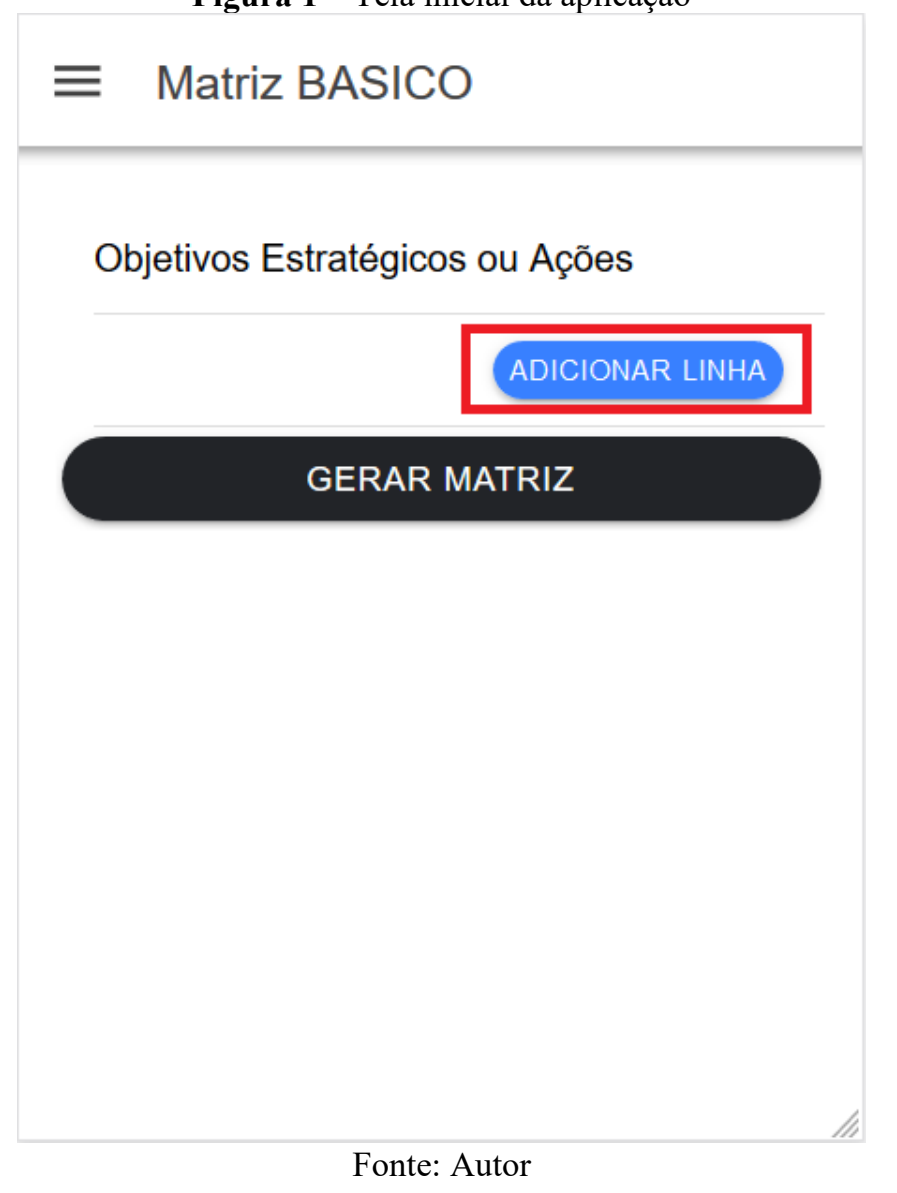

Após isso, é apresentada uma tela para se adicionar o nome da Ação Estratégica e as notas correspondentes. É preciso clicar no espaço com a palavra "Descrição" e digitar para adicionar a descrição, conforme Figura 2:

Figura 2 - Tela de adição de nova linha da Matriz 


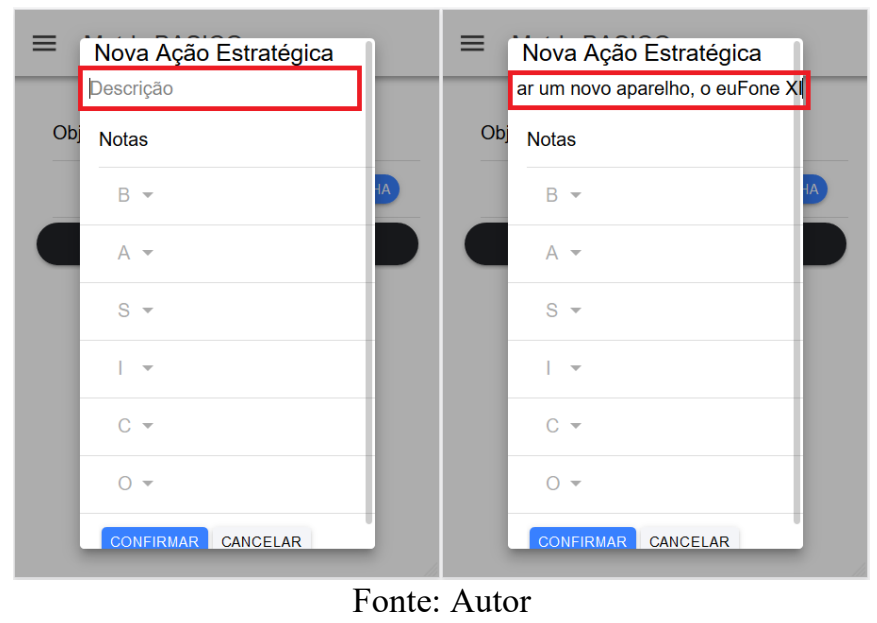

O CEO julgou as notas da Ação 1 da seguinte forma: Benefícios (B) - 4; Abrangência (A) - 2; Satisfação (S) - 4; Investimentos (I) - 5; Cliente (C) - 3; Operacionalização $(\mathrm{O})$ - 5. Para atribuir cada nota, é necessário clicar na letra correspondente, clicar num número entre 1 e 5 e então clicar no botão "Confirmar" para confirmar a nota. Após isso, é reapresentada a tela de adição de nova linha com a nova nota já inserida. A seguir, na Figura 3, demonstra-se o passo-a-passo para a nota B:

Figura 3 - Tela de inserção de nova nota 


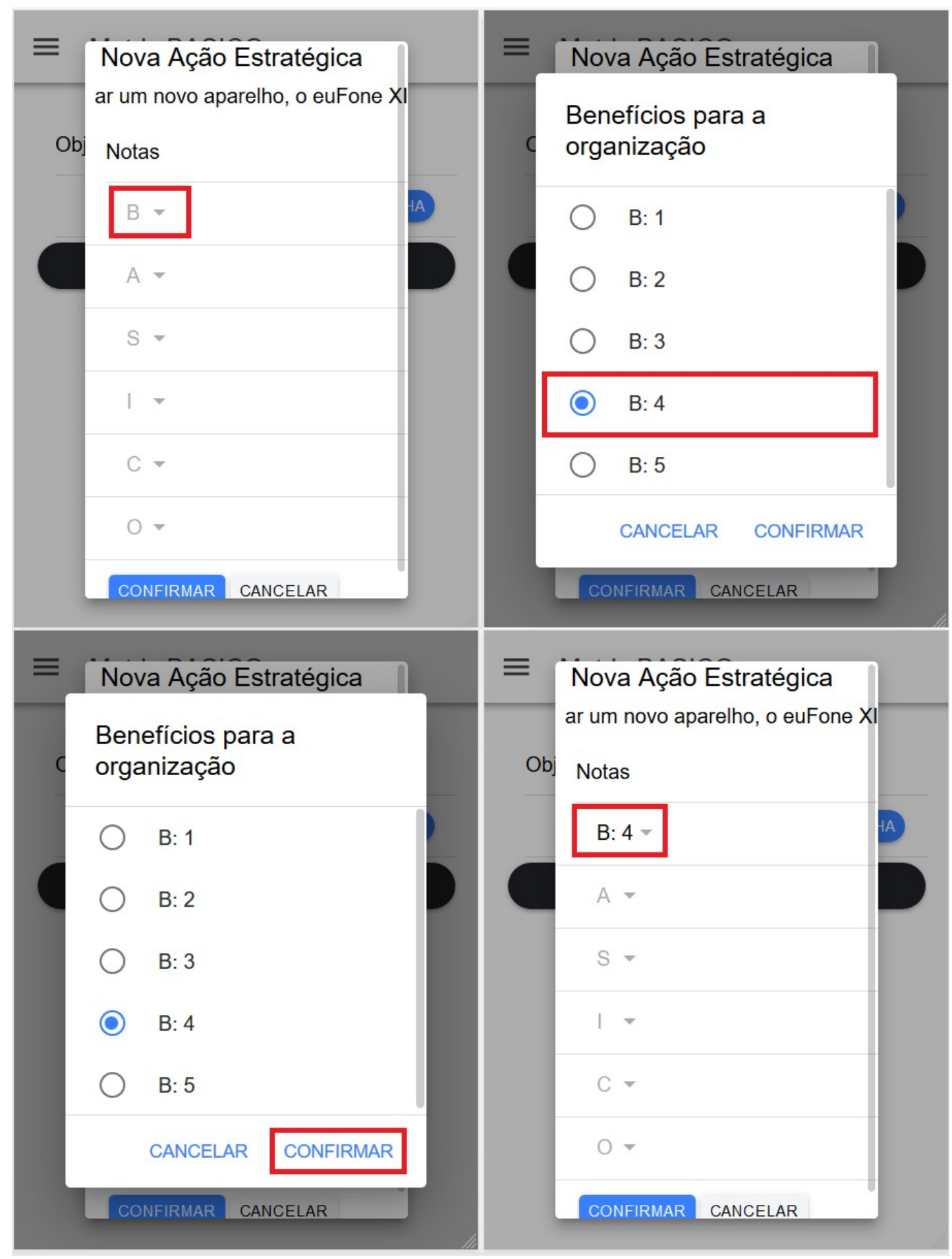

Fonte: Autor

Repetindo o mesmo processo para as outras 5 notas, é necessário clicar no botão "Confirmar" da tela de adição de nova linha para finalmente inseri-la na matriz BASICO. Em seguida, a aplicação retorna à tela inicial, agora com a nova linha adicionada. O processo se dá conforme a Figura 4 abaixo:

Figura 4 - Finalização de inserção de nova linha da Matriz 


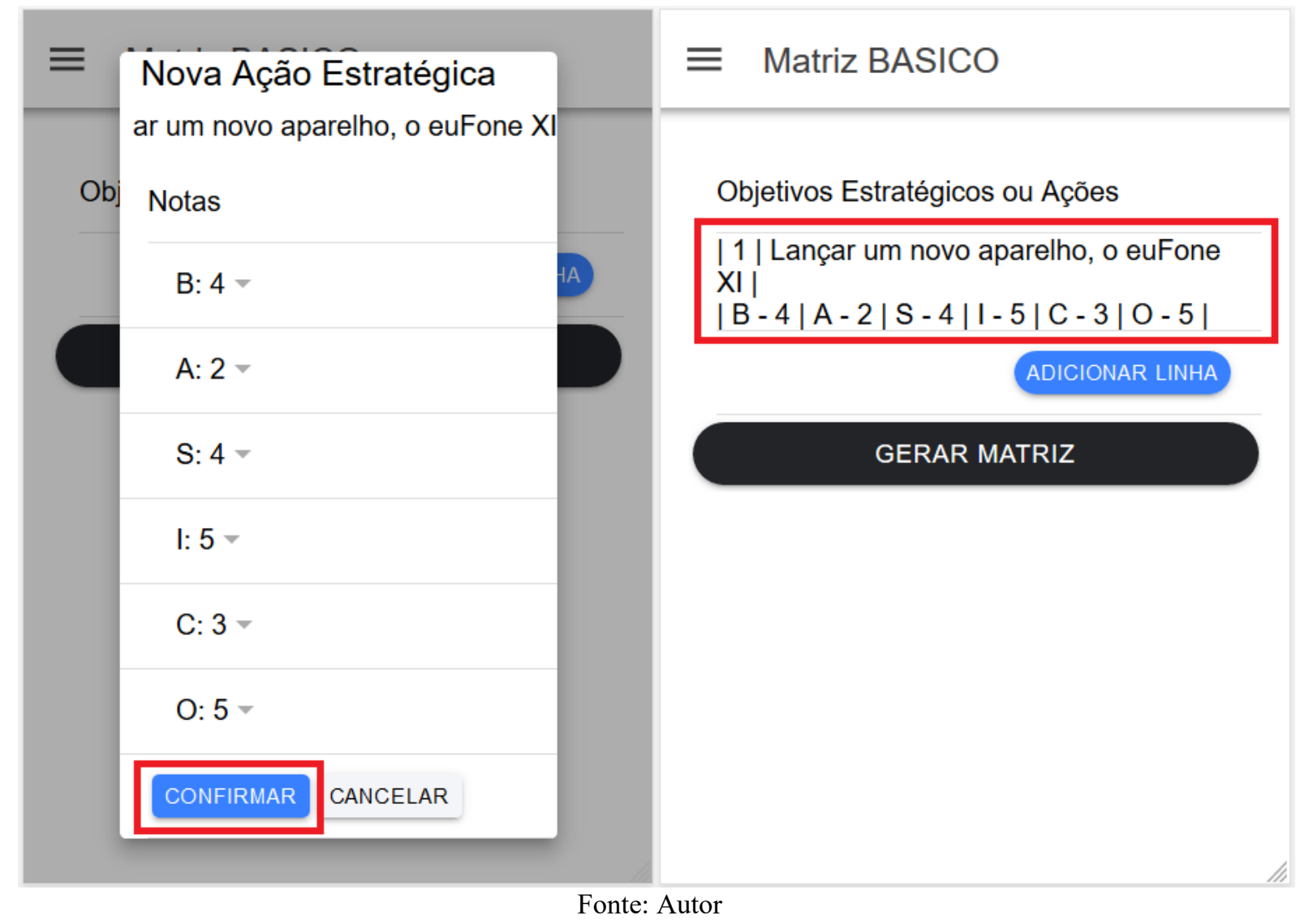

Para terminar a inserção das 7 ações, é necessário repetir o processo descrito até agora para as 6 ações restantes. Por fim, para gerar a matriz BASICO final é preciso clicar no botão "Gerar Matriz". O resultado desse processo está descrito na Figura 5 a seguir:

Figura 5 - Geração de nova Matriz BASICO 


\section{$\equiv$ Matriz BASICO}

Objetivos Estratégicos ou Ações

| 1 | Lançar um novo aparelho, o euFone XI |

| B - 4|A - 2|S - 4| - - 5| C - 3|0 - 5|

| 2 | Desenvolver um novo sistema operacional, o euOS $13 \mid$

|B - 3|A - 5|S - 4|I- $5|\mathrm{C}-4| 0$ - $2 \mid$

| 3 | Lançar campanhas de marketing do já-

existente euFone $X \mid$

$|\mathrm{B}-5| \mathrm{A}-3|\mathrm{~S}-5| \mathrm{I}-3|\mathrm{C}-5| 0-2 \mid$

| 4 | Reestruturar o quadro de funcionários, aumentando eficiência interna |

| B - 3|A - 2|S - 2|I-1|C-1|O - 1|

| 5 | Patrocinar eventos globais e nacionais de grande visibilidade |

$|\mathrm{B}-3| \mathrm{A}-4|\mathrm{~S}-2| \mathrm{I}-5|\mathrm{C}-5| 0-2 \mid$

| 6 | Criar primeiro notebook da TM, o

MequeBook |

|B - 4|A - 1|S - 4|I- $2|\mathrm{C}-3| 0-3 \mid$

| 7 | Adquirir outra companhia criadora de celulares |

$|B-1| A-4|S-4| I-3|C-1| 0-1 \mid$

\section{ADICIONAR LINHA}

\section{GERAR MATRIZ}

Fonte: Autor

Finalmente, é gerada a matriz BASICO final, com as ações estratégicas ranqueadas pela nota final, exibida na tela inicial. Para visualizar a matriz completa, é necessário rolar para baixo a página inicial. O resultado final é exibido a seguir, na Figura 6 . O resultado pode então ser usado pelo CEO para escolher objetivamente as melhores ações a serem incluídas no seu plano estratégico.

Figura 6 - Resultado da Matriz BASICO 


\section{$\equiv$ Matriz BASICO}

\section{GERAR MATRIZ}

\begin{tabular}{|c|c|}
\hline Nome & Total \\
\hline $\begin{array}{l}\text { Lançar um novo aparelho, o } \\
\text { euFone XI }\end{array}$ & 2400 \\
\hline $\begin{array}{l}\text { Desenvolver um novo sistema } \\
\text { operacional, o euOS } 13\end{array}$ & 2400 \\
\hline $\begin{array}{l}\text { Lançar campanhas de } \\
\text { marketing do já-existente } \\
\text { euFone X }\end{array}$ & 2250 \\
\hline $\begin{array}{l}\text { Patrocinar eventos globais e } \\
\text { nacionais de grande } \\
\text { visibilidade }\end{array}$ & 1200 \\
\hline $\begin{array}{l}\text { Criar primeiro notebook da } \\
\text { TM, o MequeBook }\end{array}$ & 288 \\
\hline $\begin{array}{l}\text { Adquirir outra companhia } \\
\text { criadora de celulares }\end{array}$ & 48 \\
\hline $\begin{array}{l}\text { Reestruturar o quadro de } \\
\text { funcionários, aumentando } \\
\text { eficiência interna }\end{array}$ & 12 \\
\hline
\end{tabular}

Fonte: Autor

\section{RESULTADOS ESPERADOS}

A solução apresentada, um aplicativo que oferece uma ferramenta de apoio à 
decisão aos altos gestores de organizações, é um passo inicial em direção à melhoria da governança corporativa nas instituições brasileiras. Espera-se que a objetividade agregada pela aplicação apresentada contribua para a adequação das organizações brasileiras às recomendações dos órgãos de fomento à governança no Brasil, como o Instituto Brasileiro de Governança Corporativa e o Tribunal de Contas da União. Este último apresentou um livro com passos que as organizações brasileiras deveriam seguir para melhorarem sua governança, alguns dos quais são citados a seguir e se espera atingir através do uso da aplicação (Brasil, 2014).

A alta administração, ao se utilizar de métricas objetivas para deliberar, lidera os subordinados com ética, revelando uma conduta honesta e honrada. Além disso, riscos são gerenciados quando ocorre uma análise técnica do planejamento, como através do uso da matriz BASICO. Por fim e mais importante, há um aumento considerável na transparência, tanto para os clientes externos quanto para os internos, e uma prestação de contas e responsabilização mais tangíveis quando as partes interessadas podem medir seus gestores menos subjetivamente e mais analiticamente, se utilizando de técnicas imparciais para julgar as ações que são tomadas.

Portanto, o presente trabalho desenvolvido ambiciona ser um ponto de partida para outros trabalhos na linha de apoio à decisão e de governança corporativa pública e privada. Recomenda-se o desenvolvimento de outras ferramentas matriciais, além da realização de testes de utilização e aceitação por gestores, a fim de refinar o processo de concepção dos sistemas e adequar as soluções ao público brasileiro. É necessário que as pesquisas na área de governança, tão relevante assunto para o país, continuem em crescimento, a fim de levar o Brasil a um novo patamar internacional, não só na esfera econômica, mas também social e política.

\section{CONSIDERAÇÕES FINAIS}

Acredita-se que o objetivo deste trabalho foi atingido na medida em que se apresentou um aplicativo capaz de ser utilizado em instituições públicas ou privadas em prol da boa governança. É esperado que este trabalho inspire pesquisadores, desenvolvedores e gestores a avançar na busca por criar e utilizar novas ferramentas para o desenvolvimento de uma cultura de boa governança no Brasil. Dessa forma, a sociedade brasileira poderá se beneficiar de uma gestão mais eficiente dos recursos públicos e de empresas nacionais mais conscientes e eficientes, proporcionando melhores condições de trabalho e fornecendo melhores produtos e serviços para a população.

\section{REFERÊNCIAS BIBLIOGRÁFICAS}

[1] BRASIL. Secretaria-Geral da Marinha. SGM-107 Normas Gerais de Administração. 6 Revisão, vol. 1. Brasília, 2015.

[2] . Tribunal de Contas da União. Dez passos para a boa governança. Brasília: TCU, Secretaria de Planejamento, Governança e Gestão, 2014.

[3] DE SOUZA, F.C.; BORBA, J.A. Governança corporativa e remuneração de executivos: uma revisão de artigos publicados no exterior. Contabilidade Vista \& Revista, v. 18, n. 2, p. 35-48, 2007. 
[4] HARVARD BUSINESS REVIEW. Experiências de Governança Corporativa. Rio de Janeiro: Campus, 2001.

[5] MARANHÃO, M.; MACIEIRA, M.E.B. O Processo Nosso de Cada DiaModelagem de Processos de Trabalho. 2. Ed. Rio de Janeiro: Qualitymark, 2006.

[6] MATIAS-PEREIRA, J. A governança corporativa aplicada no setor público brasileiro. Administração Pública e Gestão Social, v. 2, n. 1, p. 109-134, 2010.

[7] MELLO, G.R. de. Governança corporativa no setor público federal brasileiro. Dissertação de Mestrado. São Paulo: Universidade de São Paulo, 2006.

[8] NARDES, J.A.R.; ALTOUNIAN, C.S.; VIEIRA, L.A.G. Governança Pública: o desafio do Brasil. Belo Horizonte: Fórum, 2014.

[9] RAMOS, S.S.; VIEIRA, K.M. Matriz LIMPE: proposta de ferramenta gerencial para mensuração da governança pública municipal. TAC, Rio de Janeiro, v. 5, n. 1, p. 30$53,2015$.

[10] RICARDINO, Á.; MARTINS, S.T.A. Governança corporativa: um novo nome para antigas práticas?. Revista Contabilidade \& Finanças, v. 15, n. 36, p. 50-60, 2004.

[11] SAITO, R.; SILVEIRA, A.D.M. da. Governança corporativa: custos de agência e estrutura de propriedade. Revista de Administração de Empresas, v. 48, n. 2, p. 79 $86,2008$.

[12] SILVEIRA, A.D.M. da; BARROS, L.A.B. de C.; FAMÁ, R. Estrutura de governança e valor das companhias abertas brasileiras. Revista de Administração de Empresas, v. 43, n. 3, p. 50-64, 2003. 